\title{
LA PROTECCIÓN DE DERECHOS FUNDAMENTALES Y LIBERTADES PÚBLICAS MEDIANTE EL RECURSO DE AMPARO CONSTITUCIONAL EN ESPAÑA*
}

\section{The protection of fundamental rights and public freedoms through the constitutional appeal of amparo in Spain}

Rafael Bellido Penadés ${ }^{* *}$

\section{Resumen}

Una de las funciones del Tribunal Constitucional en España es la protección de los derechos fundamentales a través del recurso de amparo. Éste es una garantía judicial de los derechos fundamentales que ha experimentado importantes restricciones en España con la reforma de la Ley Orgánica del Tribunal Constitucional del año 2007.

\section{Recebido: 2 de junio de 2016 - Aprobado: 27 de marzo de 2017}

* Artículo inédito, que en sus líneas esenciales es fruto de la ponencia presentada en el "Congreso Internacional de Investigación en Trabajo Social y Ciencias Sociales Derechos humanos, resolución de conflictos y Postconflicto" celebrado en Armenia-Quindío (Colombia) los días 22 y 23 de octubre de 2015.

Para citar artículo: BELLIDO PENADÉS, Rafael. La protección de derechos fundamentales y libertades públicas mediante el recurso de amparo constitucional en España. Revista del Instituto Colombiano de Derecho Procesal. No. 45 Enero - Junio. 2017, pp. 127-148.

** Profesor Titular de Universidad de Derecho Procesal en la Universidad de Valencia (España). Actualmente se encuentra acreditado al cuerpo de Catedráticos de Universidad. Ex Magistrado S. de la Audiencia Provincial de Valencia. Ex Letrado del Tribunal Constitucional de España.rafael.bellido@uv.es 
La nueva regulación del recurso de amparo resulta positiva en términos de eficiencia, pero supone un retroceso en la plenitud del sistema de garantías jurisdiccionales de los derechos fundamentales, porque la lesión de un derecho fundamental, aunque sea grave, ya no es requisito suficiente para admisión del recurso de amparo por el Tribunal Constitucional.

Palabras clave: Derechos fundamentales, protección judicial, recurso de amparo, Tribunal Constitucional, reforma de la Ley Orgánica del Tribunal Constitucional.

\begin{abstract}
One of the functions of the Constitutional Court in Spain is the defense of human rights through the amparo appeals. This is a legal guarantee of fundamental rights that has experienced significant limitations in Spain with the reform of the Organic Law of the Constitutional Court in 2007. The new regulation of amparo appeals is positive in terms of efficiency, but it is a step backwards in the judicial system fully guarantees of fundamental rights, because the injury of a fundamental right, even though serious, is not sufficient requirement for admission of the amparo appeals by the Constitutional Court.
\end{abstract}

Keywords: Human rights, judicial defense, amparo appeals, Constitutional Court, reform of the Organic Law of the Constitutional Court.

\title{
Introducción
}

Las declaraciones o reconocimientos de derechos de la persona en los ordenamientos nacionales, así como en los tratados y convenios internacionales, constituyen un paso importante para la defensa y respeto de esos derechos. Sin embargo, ese reconocimiento o declaración es en sí mismo insuficiente para asegurar el respeto de los derechos en la vida social y jurídica, pues su protección y defensa efectiva pasan por el establecimiento de una serie de garantías destinadas a hacerlos valer en caso de conflicto o desconocimiento.

Esas garantías pueden ser de diferente naturaleza (legislativa, judicial, etc.). En esta ponencia nos ocuparemos de una de las garantías judiciales de los derechos fundamentales de la persona en derecho español, el recurso de amparo ante el Tribunal Constitucional, garantía que ha sido objeto de una profunda reforma mediante la modificación de la Ley Orgánica del Tribunal Constitucional de $2007^{1}$, ante la problemática que estaba generando el crecimiento progresivo de

$1 \quad$ La Ley originaria reguladora del Tribunal Constitucional es la Ley Orgánica 2/1979, de 3 de octubre, del Tribunal Constitucional, España, Cortes Generales. Salvo indicación en 
los recursos de amparo en orden al cumplimiento de las diferentes funciones encomendadas al Tribunal Constitucional ${ }^{2}$.

\section{Las funciones del Tribunal Constitucional}

El Tribunal Constitucional -regulado en el Título IX de la Carta Magna (arts. 159-165 CE³)- es el más alto tribunal de la nación española, cuya razón de ser es garantizar la efectividad de la Constitución española, siendo aquel su intérprete supremo (art. 1 LOTC $^{4}$ ).

Son múltiples las competencias que la Constitución encomienda al Tribunal Constitucional (resolver recursos de inconstitucionalidad, cuestiones de inconstitucionalidad, recurso de amparo...), autorizando así mismo que sus funciones sean incrementadas mediante ley orgánica (art. 161.4 CE).

Las funciones del Tribunal Constitucional español a groso modo pueden agruparse en tres grandes categorías: el control de la constitucionalidad de la ley y de las normas con valor de ley, la tutela jurisdiccional de los derechos fundamentales y libertades públicas a través del recurso de amparo (arts. 53. 2 y 161. $1 \mathrm{~b}$ CE) y la resolución de conflictos entre entes, poderes y órganos públicos 5 .

La primera función vendría constituida por el control de la constitucionalidad de la ley y de las normas con valor de ley, función que se cumple a través del recurso de inconstitucionalidad, de la cuestión de inconstitucionalidad y del control previo de los tratados internacionales.

contrario, las leyes a las que con carácter general nos referimos en el presente artículo son del Derecho español. Aunque la referida ley ha sido objeto de numerosas modificaciones una de las reformas de mayor envergadura de la materia es la llevada a cabo mediante la Ley Orgánica núm. 6/2007, de 24 de mayo.

2 En este sentido, ARAGÓN REYES, Manuel "La reforma de la Ley Orgánica del Tribunal Constitucional", Revista Española de Derecho Constitucional, núm. 85 de 2009, Madrid, España, Centro de Estudios Políticos y Constitucionales, pp. 12-13; BORRAJO INIESTA, Ignacio, "Mitos y realidades de la jurisdicción constitucional de amparo: hechos, derecho, pronunciamientos, admisión, costes”, Teoría E Derecho. Revista de Pensamiento Jurídico, núm. 3 de 2008, Valencia, España, Tirant lo Blanch, pp. 181 y ss.; CARRILLO, Marc, "La objetivación del recurso de amparo: una necesidad ineludible", Revista Vasca de Administración Pública, Instituto Vasco de Administración Pública, Guipúzcoa, España núm. 81 de 2008, p. 89; y FERNÁNDEZ FARRERES, Germán, "La reforma de la Ley Orgánica del Tribunal Constitucional”, Revista Española de Derecho Constitucional, núm. 81 de 2007, p. 17.

3 Constitución Española.

4 Ley Orgánica del Tribunal Constitucional.

5 ÁlVAREZ CONDE, Enrique y TUR AUSINA, Rosario, Derecho Constitucional, Madrid, Tecnos, 2014, pp. 727-780. 
El recurso de inconstitucionalidad (art. 161. 1, a CE) es un recurso directo contra normas con valor de ley de cuya inconstitucionalidad se sospecha y tiene por finalidad garantizar la supremacía de la Constitución sobre la actividad del poder legislativo ${ }^{6}$. Dicho recurso puede ser interpuesto en el plazo de tres meses desde la publicación de la norma cuestionada (art. 33 LOTC) por los órganos o agrupaciones que la propia Constitución establece: el Presidente del Gobierno, el Defensor del Pueblo, cincuenta Diputados, cincuenta Senadores, los órganos colegiados ejecutivos de las Comunidades Autónomas y, en su caso, las Asambleas de las mismas (art. 162. 1 CE).

La cuestión de inconstitucionalidad persigue así mismo asegurar la primacía de la Constitución Española y tiene su razón de ser en que el sistema español de justicia constitucional es un sistema continental o europeo de jurisdicción concentrada, en el que el Tribunal Constitucional tiene el monopolio sobre la declaración de constitucionalidad de las normas con valor de ley posteriores a la Constitución, sin que el juez ordinario pueda asegurar por sí solo el sometimiento de la ley a la Constitución. En consecuencia, "cuando un órgano judicial considere, en algún proceso, que una norma con rango de ley, aplicable al caso, de cuya validez dependa el fallo, pueda ser contraria a la Constitución, planteará la cuestión ante el Tribunal Constitucional en los supuestos, en la forma y con los efectos que establezca la ley, que en ningún caso serán suspensivos" (art. 163 $\mathrm{CE})$.

El control previo de tratados internacionales era hasta septiembre del año 2015 la única modalidad de control previo de constitucionalidad que había pervivido tras la reforma de la originaria Ley Orgánica del Tribunal Constitucional llevada a cabo en $1985^{7}$, resultando regulado en la propia Constitución (art. 95 CE) y en la Ley Orgánica del Tribunal Constitucional (art. 78). Su finalidad es evitar que mediante la ratificación de tratados internacionales se asuman obligaciones o compromisos internacionales contrarios a la Carta Magna.

Sin embargo, la reciente reforma de la Ley Orgánica del Tribunal Constitucional realizada en $2015^{8}$ ha recuperado el control previo de la constitucionalidad de los Estatutos de Autonomía y de sus reformas, una vez aprobados

6 PÉREZ TREMPS, Pablo, Derecho Constitucional, con LÓPEZ GUERRA, ESPÍN, GARCÍA MORILLO, SATRÚSTEGUI, V. II, 2010, Valencia, Tirant lo Blanch, p. 217.

7 Esta reforma fue realizada a través de la Ley orgánica 4/1985, de 7 de junio, por la que se deroga el capítulo II del título IV de la Ley orgánica 2/1979, de 3 de octubre, reguladora del Tribunal Constitucional.

8 Reforma llevada a cabo mediante la Ley Orgánica 12/2015, de 22 de septiembre, de modificación de la Ley Orgánica 2/1979, de 3 de octubre, del Tribunal Constitucional (España, Cortes Generales). 
por las Cortes Generales y antes de su entrada en vigor, otorgando al Tribunal Constitucional un plazo de seis meses para su resolución (art. 79 LOTC).

La segunda gran función del Tribunal Constitucional es la protección jurisdiccional de los derechos fundamentales y libertades públicas a través del recurso de amparo (arts. 53. 2 y 161. 1 b CE), función que constituye el eje vertebral de nuestra ponencia y que se tratará en breve.

La tercera gran función del Tribunal Constitucional es la resolución de conflictos entre entes, poderes y órganos públicos. Pueden encuadrarse en esta categoría los conflictos de competencia entre el Estado y las Comunidades Autónomas, o los de éstas entre sí (art. 161. 1 b CE), la impugnación por el Gobierno estatal de las disposiciones y resoluciones adoptadas por los órganos de las Comunidades Autónomas (art. 161. 2 CE), los conflictos en defensa de la autonomía local (arts. 59. 2 y 75 bis LOTC) y los conflictos de atribuciones entre órganos constitucionales del Estado (art. 59. 1. c LOTC).

Los conflictos de competencia entre el Estado y las Comunidades Autónomas, o los de éstas entre sí (art. 161. 1 b CE), tienen por objeto enjuiciar si el reparto de competencias entre el Estado y las CCAA, o de éstas entre sí, se ajusta al bloque de constitucionalidad, integrado básicamente por la Constitución española y los Estatutos de Autonomía; siendo, en cierto sentido, similar el conflicto en defensa de la autonomía local, cuyo objetivo básico es la tutela de la autonomía local constitucionalmente garantizada frente a lesiones derivadas de normas con fuerza de ley autonómicas o estatales. Frente a ello, la impugnación del art. 161. 2 CE conlleva el recurso contra actos o disposiciones autonómicos, en un principio, de rango inferior a la ley, que el Gobierno estatal considere contrarios a la Constitución española por razones distintas al reparto de competencias ${ }^{9}$.

Por último, corresponde al Tribunal Constitucional la resolución de los conflictos de atribuciones entre órganos constitucionales del Estado, que enfrenten al Gobierno con el Congreso de los Diputados, el Senado o el Consejo General del Poder Judicial; o a cualquiera de estos órganos constitucionales entre sí (arts. 59. 1 y 73 a 75 LOTC). No son frecuentes esta clase de conflictos, siendo de destacar, entre los clásicos, el resuelto por la STC 45/1986, de 17 de abril ${ }^{10}$, decidiendo el conflicto planteado por el Consejo General del Poder Judicial al Congreso y al Senado ante la modificación del sistema de elección de vocales del Consejo General del Poder Judicial en la Ley Orgánica del Poder Judicial

9 ÁlVAREZ CONDE, Enrique y TUR AUSINA, Rosario, Derecho..., ob. cit., p. 776.

10 Sentencia del Tribunal Constitucional (Pleno) 45/1986, de 17 de abril, Ponente Miguel Rodríguez-Piñero y Bravo-Ferrer. 
de 1985, o el resuelto por la STC 234/2000, de 3 de octubre ${ }^{11}$, que planteó el Gobierno al Senado, cuando éste inadmitió a trámite la declaración de urgencia del Gobierno para tramitar el proyecto de ley orgánica sobre regulación de la interrupción voluntaria del embarazo.

\section{La protección de derechos fundamentales mediante el recurso de amparo}

\section{1 Ámbito objetivo del recurso de amparo}

No todos los derechos reconocidos en la Constitución pueden ser protegidos mediante el recurso de amparo ante el Tribunal Constitucional, sino tan sólo aquéllos que por su carácter de fundamentales la propia Constitución establece ${ }^{12}$.

Así esta dispone que cualquier ciudadano podrá recabar la tutela de las libertades y derechos reconocidos en los artículos 14 y 30 y en la Sección primera del Capítulo $2^{\circ}$ (arts. 15 a $29 \mathrm{CE}$ ) a través del recurso de amparo ante el Tribunal Constitucional; y previamente -salvo en el caso del art. $30 \mathrm{CE}-$, ante los tribunales ordinarios mediante un procedimiento basado en los principios de preferencia y sumariedad (art. 53. 2 CE).

El primer precepto consagra el derecho a la igualdad y la prohibición de discriminación (art. 14 CE), el segundo reconoce el derecho a la objeción de conciencia (art. 30 CE) y la Sección primera (arts. 15 a 29 CE) contiene un amplio abanico de derechos fundamentales de la persona, que pasamos a enumerar.

$\mathrm{El}$ art. $15 \mathrm{CE}$ reconoce el derecho a la vida y a la integridad física y moral y prohíbe el sometimiento a tortura o a penas o tratos inhumanos o degradantes. Como consecuencia de lo primero, queda abolida la pena de muerte, salvo lo que dispongan las leyes penales militares para tiempos de guerra.

La protección del derecho a la vida y a la integridad opera tanto frente a particulares como frente a las autoridades y funcionarios, sin que por lo tanto estas puedan someter a los detenidos, presos o penados ni a torturas, ni a penas tratos inhumanos o degradantes. Una de las consecuencias de lo anterior es que la confesión obtenida con violencia durante la investigación penal es nula, carece de eficacia para desvirtuar el derecho a la presunción de inocencia.

11 Sentencia del Tribunal Constitucional (Pleno) 234/2000, de 3 de octubre, Ponente Pedro Cruz Villalón.

12 PÉREZ TREMPS, Pablo, Derecho Constitucional, con LÓPEZ GUERRA, Luis, ESPÍN, Eduardo, GARCÍA MORILLO, Joaquín, SATRÚSTEGUI, Miguel, V. II, Valencia, España, Tirant lo Blanch, 2010, p. 230. 
El art. $16 \mathrm{CE}$ proclama la libertad ideológica, religiosa y de culto de los individuos y las comunidades, en consonancia con el art. $14 \mathrm{CE}$, que proscribe la discriminación por razón de religión u opinión, y con el único límite a sus manifestaciones que el necesario para el mantenimiento del orden público.

El art. 17 CE reconoce el derecho a la libertad personal y establece una serie de derechos y garantías para quien sea privado de ella (causas determinadas por ley, derechos a la información y a la asistencia letrada del detenido, límites de duración y procedimiento de habeas corpus). Este derecho se reconoce frente a todos, frente a particulares y frente a autoridades, y especialmente frente a las autoridades y funcionarios que más frecuentemente pueden acordar las privaciones de libertad.

En el art. 18 CE se consagran diversos derechos fundamentales ligados al ámbito de la vida privada de las personas. En primer lugar, se consagran los derechos al honor, a la intimidad personal y familiar y a la propia imagen.

El derecho al honor se ha reconocido no solo a las personas individuales, sino también a las comunidades o grupos étnicos o sociales, según determinó la Sentencia núm. 214/1991 de 11 noviembre, caso Violeta Friedman, en la que se declaró la lesión del derecho al honor de la colectividad judía residente en España y se ordenó su restablecimiento.

En segundo lugar, se reconoce el derecho a la inviolabilidad de domicilio, siendo necesario para entrar en él y registrarlo, consentimiento de su titular, o autorización judicial, salvo en caso de flagrante delito.

En tercer lugar, se proclama el secreto de las comunicaciones y, en especial, de las postales, telegráficas y telefónicas, requiriéndose para su intervención autorización judicial.

El art. 19 CE consagra la libertad de movimientos, reconociendo que los españoles tienen derecho a elegir residencia y circular por el territorio nacional, así como a entrar y salir de España conforme a lo previsto en la ley, pero sin que su movilidad pueda limitarse por motivos políticos o ideológicos.

$\mathrm{El}$ art. $20 \mathrm{CE}$ reconoce distintos derechos fundamentales ligados a lo que podría denominarse latu sensu libertad intelectual. Así garantiza el derecho a la libertad de cátedra (art. 20.1. c), el derecho a la producción y creación literaria, artística, científica y técnica (art. 20. 1. b), el derecho a expresar y difundir libremente los pensamientos, ideas y opiniones mediante la palabra, el escrito o cualquier otro medio de reproducción (art. 20.1. a); y el derecho a comunicar o recibir libremente información veraz por cualquier medio de difusión (art. 20. 1. d).

Estos derechos fundamentales en ocasiones pueden colisionar con otros derechos fundamentales - caso del honor y de las libertades de expresión e 
información-y se proclaman especialmente frente a los poderes públicos, razón que lleva a que se prohíba tajantemente que el ejercicio de estos derechos pueda restringirse mediante cualquier tipo de censura previa (art. 20.2 CE), así como a que se exija resolución judicial para poder acordar el secuestro de publicaciones, grabaciones y otros medios de información (art. 20. 4 CE).

En la colisión de derechos fundamentales posee un status preferente el derecho a comunicar información, en cuanto que los medios de comunicación social con su función contribuyen a la formación de una "opinión pública libre, que es una institución ligada de manera inescindible al pluralismo político, valor esencial del Estado democrático" (STC 107/1988, de 8 de junio) ${ }^{13}$.

Por lo demás, este derecho a difundir las ideas y opiniones comprende en principio el derecho a crear los medios de comunicación a través de los cuales la difusión se hace posible (STC 12/1982 de 31 marzo) ${ }^{14}$.

En el ámbito de los derechos políticos se reconocen los derechos de reunión (art. $21 \mathrm{CE}$ ), de asociación (art. $22 \mathrm{CE}$ ), de participación en asuntos públicos y de acceso a cargos y funciones de igual naturaleza, derechos entre los que se incluyen el derecho de sufragio activo y pasivo (art. $23 \mathrm{CE}$ ).

También se reconocen derechos fundamentales de aplicación en el marco de los procesos judiciales. Así, se reconoce el derecho a la tutela judicial efectiva (art. 24. $1 \mathrm{CE}$ ), derecho fundamental cuyo contenido complejo ha ido desgranando la jurisprudencia constitucional y otros derechos fundamentales de naturaleza procesal: derecho al Juez ordinario predeterminado por la ley, a la defensa y a la asistencia de letrado, a ser informados de la acusación formulada contra ellos, a un proceso público sin dilaciones indebidas y con todas las garantías, a utilizar los medios de prueba pertinentes para su defensa, a no declarar contra sí mismo, a no confesarse culpable y a la presunción de inocencia (art. 24. $2 \mathrm{CE}$ ).

Y en línea con lo anterior se establecen límites a la potestad sancionadora, tanto a la administrativa como a la judicial. Así, se consagra como básico el principio de legalidad sancionadora (penal y administrativa), se establece la finalidad de las penas y medidas de seguridad -orientadas a la reeducación y reinserción social-y se imponen límites a la potestad sancionadora de la Administración -que no podrá imponer sanciones que impliquen privación de libertad- (art. $25 \mathrm{CE}$ ).

En el campo de los derechos sociales se reconocen el derecho a la educación y a la libertad de enseñanza -incluida la libertad de creación de centros docentes-, enseñanza que en el nivel básico es obligatoria y gratuita (art. $27 \mathrm{CE}$ ); el derecho a

13 Sentencia del Tribunal Constitucional (Sala Primera) 107/1988, de 8 de junio, Ponente Eugenio Díaz Eimil.

14 Sentencia del Tribunal Constitucional (Pleno) 12/1982 de 31 marzo, Ponente Luis DíezPicazo. 
sindicarse libremente y el derecho a la huelga de los trabajadores para la defensa de sus intereses (art. $28 \mathrm{CE}$ ). Finalmente, se proclama el derecho de petición (art. 29 CE).

Constituyendo un primer paso el reconocimiento o declaración de derechos y su calificación como fundamentales, las proclamaciones de derechos y su caracterización son en sí mismas insuficientes para la efectividad de los mismos, si no van acompañadas de garantías que los hagan valer en caso de lesión o desconocimiento.

En el caso de los derechos fundamentales reconocidos en la Constitución española la primera garantía judicial de protección de esos derechos son los procedimientos judiciales a desarrollar ante los tribunales ordinarios y el último mecanismo tuitivo ante la jurisdicción nacional es el recurso de amparo ante el Tribunal Constitucional (arts. 53. 2 y 161. 1, b CE).

\subsection{El proceso de amparo ante el Tribunal Constitucional}

El recurso de amparo protege los derechos y libertades antes relacionados frente a cualquier vulneración procedente de los poderes públicos -sólo indirectamente respecto de los actos con valor de ley del poder legislativo (autocuestión de inconstitucionalidad)-, o, incluso, contra lesiones de derechos fundamentales causadas por particulares, en la medida en que, si no son reparadas por los órganos judiciales, la jurisprudencia del Tribunal Constitucional considera imputable la lesión del derecho fundamental al órgano judicial, que forma parte del poder público ${ }^{15}$.

La legitimación para interponer el recurso de amparo se reconoce al Defensor del Pueblo, al Ministerio Fiscal y a toda persona física o jurídica que invoque un interés legítimo (art. 162, b CE), cualidad que sin duda posee quien ha sido parte en el proceso judicial previo (art. $46.1 \mathrm{~b}$ LOTC) y considera vulnerado un derecho fundamental.

El plazo para presentar el recurso difiere según los actos contra los que se dirige: si se dirige contra actos sin valor de ley de órganos legislativos, el plazo es de tres meses desde su firmeza (art. 42 LOTC); si se dirige contra actos de órganos gubernativos, el plazo es de veinte días desde que se notifique la resolución que agote la vía judicial previa (art. 43. 2 LOTC); y, finalmente, si se dirige contra actos de órganos judiciales, el plazo es de treinta días desde que se notifique la resolución impugnada (art. 44. 2 LOTC).

15 PÉREZ TREMPS, Pablo, Derecho Constitucional, con LÓPEZ GUERRA, Luis, ESPÍN Eduardo, GARCÍA MORILLO, Joaquín, SATRÚSTEGUI, Miguel, V. II, Valencia, España, Tirant lo Blanch, 2010, p. 231. 
El procedimiento es sencillo, se inicia mediante demanda escrita, en la que se expondrán con claridad y concisión los hechos que la fundamenten, se citarán los preceptos constitucionales que se estimen infringidos y se fijará con precisión el amparo que se solicita. En todo caso, la demanda justificará la especial trascendencia constitucional del recurso (art. 49. 1 LOTC) y deben acompañarse algunos documentos (poder al procurador, certificación de resolución impugnada) y copia de la misma para otras partes.

Tras la presentación de la demanda y un primer control por las Secretarías de Justicia, las Secciones -con las precisiones que después se harán- deben resolver sobre la admisión o inadmisión a trámite del recurso de amparo.

Si se dicta providencia de inadmisión, el proceso de amparo finaliza, salvo que la providencia sea recurrida por el Ministerio Fiscal (art. 49. 3 LOTC).

Si se dicta providencia de admisión, el proceso de amparo continúa, requiriendo al órgano judicial que conoció del proceso judicial previo que remita las actuaciones y que emplace a las partes para comparecer ante el Tribunal Constitucional (art. 51 LOTC).

Una vez recibidas las actuaciones, la Sala da vista a las partes y al Ministerio Fiscal para que presenten alegaciones en el plazo de veinte días.

Presentadas las alegaciones o transcurrido el plazo para hacerlo, la Sala podrá deferir la resolución del recurso a una de sus Secciones, cuando para su resolución sea aplicable doctrina consolidada del Tribunal Constitucional, o, en otro caso, señalar día para la vista, o para deliberación y votación.

La Sala, o la Sección, pronunciarán la sentencia que proceda en el plazo de diez días (art. 51 LOTC), concediendo o denegando el amparo.

Si lo concede, la sentencia contendrá alguno o algunos de los pronunciamientos siguientes: declaración de nulidad del acto o resolución impugnada, reconocimiento del derecho o libertad pública vulnerado y restablecimiento del recurrente en la integridad de su derecho, con adopción de las medidas apropiadas para eso (art. 55 LOTC).

\subsection{Las modificaciones introducidas en el recurso de amparo por la Ley Orgánica 6/2007}

La reforma de la Ley Orgánica del Tribunal Constitucional llevada a cabo en $2007^{16}$, tuvo como principal finalidad "reordenar la dedicación que el Tribunal

16 Una de las reformas de la Ley Orgánica del Tribunal Constitucional de mayor envergadura de la materia es precisamente la llevada a cabo mediante la Ley Orgánica núm. 6/2007, de 24 de mayo (España, Cortes Generales). 
Constitucional otorga a cada una de sus funciones para cumplir adecuadamente con su misión constitucional" (EM, I, párrafo $2^{\circ}$ ), por los problemas que se habían generado tras la experiencia acumulada de veinticinco años de actividad del Tribunal Constitucional. "Por un lado, el crecimiento del número de recursos de amparo hasta el punto de ocupar casi todo el tiempo y los medios materiales y personales del Tribunal. Por otro lado, la realidad de los hechos ha permitido también constatar la lentitud de los procedimientos que se desarrollan ante este Alto Tribunal" (EM, II, párrafo $1^{\circ}$ ).

Con dichos precedentes analizaremos a continuación las principales reformas introducidas con relación al recurso de amparo por la LO 6/2007.

En primer lugar, con el fin de agilizar la resolución de los recursos de amparo, se introducen modificaciones en orden al órgano competente para decidir en Sentencia el recurso de amparo.

Como es sabido, el Tribunal Constitucional puede actuar a través del Pleno, de las Salas y de las Secciones. El Pleno está integrado por todos los Magistrados del Tribunal, doce (art. 6 LOTC). Así mismo, el Tribunal Constitucional consta de dos Salas y cada Sala está compuesta por seis Magistrados nombrados por el Tribunal en Pleno (art. 7 LOTC). Por último, para el despacho ordinario y la decisión o propuesta, según proceda, sobre la admisibilidad o inadmisibilidad de procesos constitucionales, el Pleno y las Salas constituyen Secciones compuestas por el respectivo Presidente o quien le sustituya y dos Magistrados (art. 8. 1 LOTC).

Con anterioridad a la reforma, la competencia para la resolución de los recursos de amparo correspondía a las Salas, salvo que el Pleno recabara alguno para sí (arts. 48 y 10, K LOTC). En cambio, la resolución sobre la admisión a trámite del recurso correspondía a las Secciones (art. 8. 1 y 50 LOTC) Sin embargo, con la reforma de 2007 se incrementa el número de órganos competentes para la resolución de los recursos de amparo, pues a la competencia tradicional del Pleno (único) y de las Salas de Justicia (dos) se añade la competencia de las Secciones (cuatro) (art. 48 LOTC), si la Sala decide deferir a alguna de sus Secciones "la resolución del recurso, cuando para su resolución sea aplicable doctrina consolidada del Tribunal Constitucional" (art. 52. 2 LOTC).

En segundo lugar, las modificaciones más importantes son las relativas al régimen de admisión a trámite del recurso de amparo. Unas modificaciones se refieren a los requisitos de los que depende la admisión a trámite del recurso, y otras modificaciones se refieren al régimen de mayorías necesario para adoptar la decisión de admisión o inadmisión a trámite e, incluso, al órgano competente para decidir sobre el particular. 
Comenzando por la segunda cuestión es de señalar que, con anterioridad a la reforma de 2007, sobre la admisión o inadmisión a trámite decidía siempre el mismo órgano, la Sección (arts. 8. 1 y 50 LOTC). Si bien el procedimiento y el régimen de mayorías era diferente según el caso fuera de admisión a trámite, o de inadmisión.

La decisión de admisión a trámite podía acordarse por la Sección por simple mayoría mediante providencia (arts. 80 y 90 LOTC).

Por el contrario, la decisión de inadmisión a trámite podía adoptarse mediante providencia -que no exige motivación- por la Sección si existía unanimidad, mientras que si solo existía mayoría - pero no unanimidad- la inadmisión debería acordarse por la Sección mediante auto - que exige motivación-y previa audiencia del demandante y del Ministerio Fiscal.

En cambio, tras la reforma de la LO 6/2007, se ha endurecido el régimen de admisión del recurso de amparo y se ha flexibilizado el régimen para su inadmisión. Así, para la admisión a trámite del recurso ya no basta el acuerdo de la mayoría de la Sección, siendo precisa la unanimidad de ésta para acordar la admisión del recurso y, si solo hubiera acuerdo de la mayoría de la Sección, ésta debe trasladar el asunto a la Sala para que sea ella quien decida sobre la admisión del recurso (art. 50. 2 LOTC) ${ }^{17}$.

Por el contrario, se ha relajado el régimen de mayorías necesario para acordar la inadmisión a trámite, que se llevará a cabo siempre mediante providencia (art. 50.1 y 3 LOTC), adoptada por simple mayoría de la Sección (art. 90 LOTC) y sin necesidad de dar previa audiencia al demandante ni al Ministerio Fiscal.

Por lo demás, los requisitos de la providencia que acuerde la inadmisión, de derecho, no son muy diferentes antes o después de la reforma de 2007. Antes de la reforma, la ley disponía que la providencia de inadmisión "indicará el supuesto en el que se encuentra el recurso” (art. 50. 2 LOTC), es decir, que expresará cuál es la causa de inadmisión apreciada. Tras la reforma se establece que las providencias de inadmisión "especificarán el requisito incumplido" (art. 50. 3 LOTC). En consecuencia, los requisitos de la providencia de inadmisión en el plano legal son muy similares.

Sin embargo, en la práctica del Tribunal Constitucional la situación sí ha cambiado, porque, con anterioridad a la reforma, aunque la ley no les obligara,

17 Esa elevación del quorum necesario para la admisión a trámite del recurso de amparo ha llegado a considerarse como la reforma más profunda introducida por la Ley Orgánica 6/2007. Vid. BORRAJO INIESTA, Ignacio, "Mitos y realidades de la jurisdicción constitucional de amparo: hechos, derecho, pronunciamientos, admisión, costes", Teoría E Derecho. Revista de Pensamiento Jurídico, núm. 3 de 2008, Valencia, España, Tirant lo Blanch, p. 192. 
las Secciones del Tribunal Constitucional dictaban providencias motivadas en las que se explicaban con razonable extensión los motivos de la inadmisión. En cambio, tras la reforma de 2007, las providencias de las Secciones y Salas del Tribunal se limitan a cumplir la ley, especificando el requisito incumplido.

Ahora bien, las modificaciones más importantes son las relativas a los requisitos de los que depende la admisión a trámite del recurso. La decisión de admisión a trámite del recurso de amparo está sometida al cumplimiento de unos requisitos formales y de otros requisitos de fondo.

Por lo que respecta a los requisitos formales, en general no son afectados de modo sustancial por la reforma, tampoco los requisitos de los recursos de amparo dirigidos frente a una resolución judicial, pues, aún con ciertas modificaciones terminológicas, se mantienen los requisitos de agotamiento de los recursos procedentes en la vía judicial previa, de imputabilidad de la violación del derecho o libertad al órgano judicial y de pronta denuncia formal de la vulneración del derecho en el proceso judicial previo seguido ante los tribunales ordinarios (art. 44. 1 LOTC).

La principal reforma en este aspecto es la modificación del plazo de interposición del recurso de amparo dirigido contra resoluciones judiciales, que pasa de veinte a treinta días desde la notificación de la resolución judicial a recurrir, ampliación que tiene su razón de ser en la mayor complejidad y laboriosidad de la elaboración del recurso ante la necesidad de justificar el nuevo requisito de fondo al que a continuación nos referimos.

Sin embargo, el núcleo vertebral de la reforma se refiere a los requisitos de fondo de los que depende la admisión del recurso de amparo y, más en particular, al nuevo requisito consistente en la especial trascendencia constitucional del recurso de amparo (arts. 48. 1 y 50.1, b LOTC).

Antes de la reforma realizada por la LO 6/2007, había dos supuestos en los que podía acordarse la inadmisión del recurso de amparo por razones de fondo: que el recurso "carezca manifiestamente de contenido que justifique una decisión sobre el fondo" amparo (art. 50.1, c LOTC), y "que el Tribunal Constitucional hubiera desestimado ya en el fondo un recurso o cuestión de inconstitucionalidad o un recurso de amparo en supuesto sustancialmente igual" (art. 50.1, d LOTC).

Estas causas de inadmisión formalmente han desaparecido de modo expreso de la ley, pero el Tribunal las sigue aplicando, al menos, la relativa a la carencia manifiesta de contenido (art. 50.1, c LOTC), según se desprende de la Memoria del Tribunal Constitucional de 2014.

Con todo, como se adelantaba, la mayor novedad de la reforma de 2007 consiste en la introducción como nuevo requisito de admisión del recurso 
de amparo de la especial trascendencia constitucional del recurso, como ha destacado la jurisprudencia constitucional.

En este sentido, la STC 155/2009, de 25 de junio, pone de manifiesto que "constituye el elemento más novedoso o la "caracterización más distintiva» (ATC 188/2008, de 21 de julio, F. 3) de esta regulación del recurso de amparo el requisito sustantivo o de fondo de la «especial trascendencia constitucional» que impone el art. 50.1 b) LOTC para la admisión del recurso. En él se plasma la opción del legislador (...), por una nueva configuración del recurso de amparo, toda vez que, en principio, tras la reforma llevada a cabo la mera lesión de un derecho fundamental o libertad pública tutelable en amparo ya no será por sí sola suficiente para admitir el recurso, pues es imprescindible, además, su «especial trascendencia constitucional», frente a la configuración por la que esencialmente se caracterizaba en su anterior regulación, en tanto que recurso orientado primordialmente a reparar las lesiones causadas en los derechos fundamentales y libertades públicas del demandante susceptibles de amparo. Así pues, para la admisión del recurso de amparo no es suficiente la mera lesión de un derecho fundamental o libertad pública del recurrente tutelable en amparo [arts. 53.2 y 161.1 b) CE y 41 LOTC], sino que además es indispensable, en lo que ahora interesa, la especial trascendencia constitucional del recurso [art. $50.1 \mathrm{~b}$ ) LOTC]. El recurso de amparo, en todo caso, sigue siendo un recurso de tutela de derechos fundamentales".

Del texto transcrito de la anterior sentencia deben destacarse tres ideas: que la introducción del requisito de la «especial trascendencia constitucional» es el elemento más novedoso; que el recurso de amparo, en todo caso, sigue siendo un recurso de tutela de derechos fundamentales, razón que justifica que se siga aplicando la causa de inadmisión de la carencia manifiesta de contenido contenida en el art. 50. 1, c LOTC antes de la reforma; y, sobre todo, que la violación de un derecho fundamental consagrado en la Constitución española ya no es motivo suficiente para la admisión del recurso de amparo, ya que es preciso, además, que el recurso presente «especial trascendencia constitucional» ${ }^{18}$.

Ahora en qué consiste la especial trascendencia constitucional del recurso es el verdadero puns dolens de todo recurso de amparo, pues constituye una carga del recurrente justificar en el recurso su especial trascendencia constitucional (arts. 48.1 y 50. 1, b LOTC).

La Ley Orgánica 6/2007 ofreció unos iniciales criterios orientadores que auxiliaran al justiciable en la determinación de este requisito, al establecer

18 Sentencia del Tribunal Constitucional (Pleno) 155/2009, de 25 de junio, Ponente Vicente Conde Martín de Hijas. 
que la concurrencia de una especial trascendencia constitucional "se apreciará atendiendo a su importancia para la interpretación de la Constitución, para su aplicación o para su general eficacia, y para la determinación del contenido y alcance de los derechos fundamentales" (art. $50.1 \mathrm{~b}$ LOTC).

Sin embargo, los criterios legales son suficientemente amplios como para dotar de un vasto margen de apreciación al Tribunal Constitucional, margen que éste ha tratado de reducir de modo provisional en aras a una mayor seguridad jurídica en la STC 155/2009. En ella el alto tribunal considera que cabe estimar la concurrencia de especial trascendencia constitucional en los casos siguientes: "a) el de un recurso que plantee un problema o una faceta de un derecho fundamental susceptible de amparo sobre el que no haya doctrina del Tribunal Constitucional, supuesto ya enunciado en la STC 70/2009, de 23 de marzo; b) o que dé ocasión al Tribunal Constitucional para aclarar o cambiar su doctrina, como consecuencia de un proceso de reflexión interna, como acontece en el caso que ahora nos ocupa, o por el surgimiento de nuevas realidades sociales o de cambios normativos relevantes para la configuración del contenido del derecho fundamental, o de un cambio en la doctrina de los órganos de garantía encargados de la interpretación de los tratados y acuerdos internacionales a los que se refiere el art. 10.2 CE; c) o cuando la vulneración del derecho fundamental que se denuncia provenga de la Ley o de otra disposición de carácter general; d) o si la vulneración del derecho fundamental traiga causa de una reiterada interpretación jurisprudencial de la Ley que el Tribunal Constitucional considere lesiva del derecho fundamental y crea necesario proclamar otra interpretación conforme a la Constitución; e) o bien cuando la doctrina del Tribunal Constitucional sobre el derecho fundamental que se alega en el recurso esté siendo incumplida de modo general y reiterado por la jurisdicción ordinaria, o existan resoluciones judiciales contradictorias sobre el derecho fundamental, ya sea interpretando de manera distinta la doctrina constitucional, ya sea aplicándola en unos casos y desconociéndola en otros; f) o en el caso de que un órgano judicial incurra en una negativa manifiesta del deber de acatamiento de la doctrina del Tribunal Constitucional (art. 5 de la Ley Orgánica del Poder Judicial: LOPJ; g) o, en fin, cuando el asunto suscitado, sin estar incluido en ninguno de los supuestos anteriores, trascienda del caso concreto porque plantee una cuestión jurídica de relevante y general repercusión social o económica o tenga unas consecuencias políticas generales, consecuencias que podrían concurrir, sobre todo, aunque no exclusivamente, en determinados amparos electorales o parlamentarios".

Ahora bien, lo anterior no supone que el Tribunal Constitucional haya renunciado al amplio margen decisorio que en la admisión del recurso del amparo le atribuyó la reforma legal de 2007 con la introducción de este nuevo requisito, pues el tribunal en la referida sentencia no dejó de señalar "sin que 
la relación que se efectúa pueda ser entendida como un elenco definitivamente cerrado de casos en los que un recurso de amparo tiene especial trascendencia constitucional, pues a tal entendimiento se opone, lógicamente, el carácter dinámico del ejercicio de nuestra jurisdicción, en cuyo desempeño no puede descartarse a partir de la casuística que se presente la necesidad de perfilar o depurar conceptos, redefinir supuestos contemplados, añadir otros nuevos o excluir alguno inicialmente incluido".

Con todo, lo más grave de la reforma no es el amplio poder hermenéutico otorgado al tribunal, sino la desnaturalización del recurso de amparo, que deja de ser una garantía eficaz para la protección de toda vulneración de derechos fundamentales. En otros términos, la lesión de un derecho fundamental en el Derecho español actual es por sí misma insuficiente para franquear la puerta del amparo ante el Tribunal Constitucional, pues es preciso para ello que, además de la vulneración del derecho o libertad, el recurso presente especial trascendencia constitucional. En otros términos, lo esencial para la admisión a trámite del recurso de amparo deja de ser que se haya producido la lesión de un derecho fundamental, siendo ahora lo determinante que el recurso sea "constitucionalmente interesante" 19 , quedando por tanto inermes -por graves que sean-, ante el cierre de la puerta del amparo constitucional, las vulneraciones de derechos fundamentales que no reúnan dicha condición.

De esta forma se sacrifica en buena medida la función del Tribunal Constitucional de protección de los derechos fundamentales a través del recurso de amparo en provecho de las otras funciones del Tribunal Constitucional antes expuestas, de modo diferente a como sucede en otros ordenamientos jurídicos avanzados, como en el de Estados Unidos o en el de Alemania, en los que no se cercena de modo absoluto la dimensión subjetiva del recurso de amparo ${ }^{20}$.

Como consecuencia de lo anterior, sabedor el legislador de la merma que para la protección de los derechos fundamentales puede suponer la nueva regulación del recurso de amparo, trató en cierto modo de compensar esa restricción de la tutela de los derechos fundamentales ante el Tribunal Constitucional, con una mayor protección de los derechos y libertades fundamentales ante los tribunales de la jurisdicción ordinaria.

19 DE LA OLIVA SANTOS, Andrés, "La perversión jurídica del amparo constitucional en España”, Actualidad Jurídica Aranzadi, núm. 751 de 2008, Editorial Aranzadi, Navarra, España, apartado VIII in fine.

20 HERNÁNDEZ RAMOS, Mario, "Propuesta de desarrollo del nuevo trámite de admisión del recurso de amparo: aspectos materiales y procedimentales”, Revista de Las Cortes Generales, núm. 73 de 2008, Madrid, España, Congreso de los Diputados, pp. 39, 44 y 52-54. 
En este sentido se justifica el legislador en la Exposición de Motivos de la ley de reforma, que se expresa en los siguientes términos: "La protección y garantía de los derechos fundamentales no es una tarea única del Tribunal Constitucional, sino que los tribunales ordinarios desempeñan un papel esencial y crucial en ella. Por ello, y con la intención de aumentar las facultades de la jurisdicción ordinaria para la tutela de los derechos fundamentales se modifica el incidente de nulidad de actuaciones del artículo 241.1 de la Ley Orgánica 6/1985, de 1 de julio. De este modo se introduce una configuración del incidente de nulidad de actuaciones mucho más amplia, porque se permite su solicitud con base en cualquier vulneración de alguno de los derechos fundamentales referidos en el artículo 53.2 de la Constitución en lugar de la alegación de indefensión o incongruencia prevista hasta el momento. Esta ampliación del incidente de nulidad de actuaciones previo al amparo busca otorgar a los tribunales ordinarios el papel de primeros garantes de los derechos fundamentales en nuestro ordenamiento jurídico".

Sin embargo, pese a la buena intención del legislador, el instrumento elegido para potenciar la protección de los derechos fundamentales ante los tribunales ordinarios -el incidente de nulidad de actuaciones (art. 241 LOPJ)- resulta profundamente ineficaz, como ha puesto de manifiesto en numerosas ocasiones la doctrina, sobre todo, porque confía la resolución del incidente al mismo órgano judicial que ha dictado la resolución judicial impugnada ${ }^{21}$, es decir, atribuye la resolución del incidente al propio autor de la supuesta vulneración del derecho fundamental para que reconsidere y, en su caso, rectifique su actuación.

\subsection{La realidad del amparo constitucional en la actualidad}

Una vez expuesto el sentido de la reforma conviene analizar su alcance en el banco de pruebas de la práctica. La reforma tenía por objeto reasignar el tiempo que el Tribunal Constitucional dedicaba a sus distintas funciones, debido a que, tradicionalmente, la mayor parte de su tiempo lo ocupaba el recurso de amparo, cuyo crecimiento era continuo.

21 FERNÁNDEZ FARRERES, Germán, “La reforma de la Ley Orgánica..., ob. cit., p. 29; CABANAS GARCÍA, Juan Carlos, "El recurso de amparo que queremos", Revista Española de Derecho Constitucional, núm. 88 de 2010, Madrid, España, Centro de Estudios Políticos y Constitucionales, p. 52 y CARRERAS SERRA, Francesc de, "Una interpretación moderadamente optimista del nuevo recurso de amparo", Parlamento y Constitución. Anuario, núm. 11 de 2008, Cortes de Castilla-La Mancha, Toledo, España, p. 26. 
Si se examina la evolución del recurso de amparo en España, se aprecia que el crecimiento de los recursos de amparo desde la inicial década de los años ochenta hasta la reforma de 2007 ha sido constante y vertiginoso ${ }^{22}$.

\begin{tabular}{|l|r|r|r|r|r|r|r|}
\hline & $\mathbf{2 0 0 2}$ & \multicolumn{1}{c|}{$\mathbf{2 0 0 3}$} & \multicolumn{1}{c|}{$\mathbf{2 0 0 4}$} & \multicolumn{1}{c|}{$\mathbf{2 0 0 5}$} & \multicolumn{1}{c|}{$\mathbf{2 0 0 6}$} & \multicolumn{1}{c|}{$\mathbf{2 0 0 7}$} & $\mathbf{2 0 0 8}$ \\
\hline Amparos ingresados & 7.285 & 7.721 & 7.814 & 9.476 & 11.471 & 9.840 & 10.279 \\
\hline Amparos resueltos & 5.611 & 6.658 & 7.109 & 6.078 & 8.368 & 11.393 & 12.833 \\
\hline $\begin{array}{l}\text { Amparos pendientes } \\
\text { de sentencia }\end{array}$ & 363 & 428 & 505 & 412 & 277 & 313 & 304 \\
\hline $\begin{array}{l}\text { Amparos pendientes } \\
\text { de admisión }\end{array}$ & 6.040 & 7.071 & 7.580 & 10.990 & 13.883 & 12.166 & 6.040 \\
\hline
\end{tabular}

\begin{tabular}{|l|r|r|r|r|r|r|r|}
\hline & \multicolumn{1}{|c|}{$\mathbf{2 0 0 9}$} & \multicolumn{1}{c|}{$\mathbf{2 0 1 0}$} & \multicolumn{1}{c|}{$\mathbf{2 0 1 1}$} & \multicolumn{1}{c|}{$\mathbf{2 0 1 2}$} & \multicolumn{1}{c|}{$\mathbf{2 0 1 3}$} & $\mathbf{2 0 1 4}$ & $\mathbf{2 0 1 5}$ \\
\hline Amparos ingresados & 10.792 & 8.947 & 7.098 & 7.205 & 7.376 & 7.663 & 7.203 \\
\hline Amparos resueltos & 15.693 & 10.110 & 6.584 & 7.472 & 6.012 & 6.882 & - \\
\hline $\begin{array}{l}\text { Amparos pendientes } \\
\text { de sentencia }\end{array}$ & 173 & 200 & 145 & 141 & 167 & 116 & 99 \\
\hline $\begin{array}{l}\text { Amparos pendientes } \\
\text { de admisión }\end{array}$ & 4.569 & 3.149 & 3.420 & 2.895 & 3.738 & - & 3.312 \\
\hline
\end{tabular}

Durante los primeros años (1980-1985) las cifras iban desde los 218 recursos de amparo ingresados en 1980 a los 969 de 1985, sin que en esos años se alcanzara el millar. La unidad de millar se alcanzó en el bienio 1986-1987, superándose las dos unidades de millar en los años 1988-1991, las tres unidades de millar en los años 1992-1993, las cuatro unidades de millar en los años 1994-1996, las cinco unidades de millar en los años 1997-1999, las seis unidades de millar en los años 2000-2001 y las siete unidades de millar en los años 2002-2004. El crecimiento fue mucho mayor en los años siguientes, alcanzando los 9.476 recursos en 2005 y los 11.471 en $2006^{23}$.

22 Los datos que figuran en los cuadros siguientes han sido extraídos de las memorias del Tribunal Constitucional publicadas en http://www.tribunalconstitucional.es/es/ LeyTransparencia/informacionInstitucional/memorias/Paginas/default_05.aspx. El guión (-) del segundo cuadro significa que la fuente consultada no refleja un dato en un año concreto.

23 Los recursos de amparo ingresados entre 1980 y 2001 fueron 218 en el año 1980, 386 en el año 1981, 434 en el año 1982, 827 en el año 1983, 807 en el año 1984, 969 en el año 1985, 1225 en el año 1986, 1655 en el año 1987, 2125 en el año en el año 1988, 2603 en el año 1989, 2896 en el año 1990, 2698 en el año 1991, 3226 en el año 1992, 3874 en el año 1993, 4161 en el año 1994, 4369 en el año 1995, en el 4689 año 1996, 5391 en el año 1997, 5441 en el año 1998, 5582 en el año 1999, 6762 en el año 2000, 6786 en el año 2001. Cfr. HERNÁNDEZ RAMOS, Mario, “Propuesta de desarrollo...”, ob. cit., p. 58.

144 Revista del Instituto Colombiano de Derecho Procesal • No. 45 
Tras la aprobación de la reforma de 2007, el ingreso de recursos de amparo ha dejado de crecer de forma constante. Es más la entrada de recursos de amparo ha comenzado a decrecer paulatinamente. En el año 2007 los recursos de amparo ingresados decrecieron por primera vez, registrándose 9.840 frente a los más de 11.000 del año anterior. Sin embargo, el número de recursos aumentó en los dos años siguientes, alcanzándose los 10.279 recursos en 2008 y los 10.792 en 2009, aumento que puede tener su causa en el tiempo empleado por el Tribunal para ofrecer una interpretación del significado del nuevo requisito de la especial trascendencia constitucional y por los abogados para percibir el alcance de la reforma. A partir del año 2010 el número de recursos de amparo que entran anualmente ha ido disminuyendo progresivamente, estabilizándose el ingreso de recursos de amparo desde el año 2011 en algo más de los siete mil recursos de amparo anuales ${ }^{24}$.

No obstante, junto al número de recursos de amparo ingresados, conviene también hacer referencia a otros parámetros, a fin de valorar la eficiencia de la reforma en orden a la tramitación y resolución de los recursos de amparo, aunque se acoten algo en el tiempo.

De los datos expuestos en los dos cuadros anteriores se desprende que la reforma de 2007 ha influido positivamente en la eficiencia de la resolución de los recursos de amparo. Por una parte, el ingreso de recursos de amparo ha comenzado a invertir su evolución, pues el tradicional crecimiento progresivo de los recursos de amparo va dando lugar a un fenómeno de decrecimiento constante desde el año 2010.

Por otra parte, disminuyendo la entrada de los recursos de amparo, aumenta su salida, como lo evidencia el hecho de que descienda considerablemente el número de recursos pendientes de sentencia, una vez admitidos, así como que disminuyan también sustancialmente los recursos de amparo pendientes de una decisión inicial de admisión o inadmisión. Así, vemos que el número de recursos de amparo pendientes de sentencia, que en los años 2002 a 2006 rondaban entre los 300 y 500 anuales, con posterioridad a 2008 se sitúan entre los 150 y 170 anuales, y constatamos que el año 2014 terminó con poco más de un centenar de recursos pendientes de sentencia (116 recursos) y el año 2015 con menos de un centenar ( 99 recursos). E, igualmente, la tendencia es positiva con respecto a los recursos de amparo pendientes de decisión sobre admisión a trámite, que en los inmediatos años anteriores a la reforma rebasaban anualmente los 10.000 asuntos pendientes, mientras que, con posterioridad, la

24 En concreto, ingresaron 8.947 recursos de amparo en 2010, 7.098 en 2011, 7.205 en 2012, 7.376 recursos en 2013, 7.663 recursos en 2014 y 7.203 recursos en 2015. 
media de recursos de amparo pendientes de decisión sobre admisión a trámite se sitúa anualmente en torno a los 3.000 recursos.

\section{Conclusiones}

La conclusión que cabe extraer es que el recurso de amparo es una garantía para la efectividad de los derechos fundamentales, que en España ha experimentado importantes restricciones con la reforma de 2007, como consecuencia de la introducción del requisito de la especial trascendencia constitucional.

La nueva regulación del recurso de amparo resulta positiva en términos de eficiencia, como demuestra la práctica de la actuación del Tribunal Constitucional de los años posteriores a aquella. Sin embargo, supone un retroceso en la plenitud del sistema de garantías jurisdiccionales de los derechos y libertades fundamentales, toda vez que las lesiones de derechos y libertades fundamentales que no posean especial trascendencia constitucional, por muy graves que sean, no podrán ser declaradas ni reparadas en amparo por el Tribunal Constitucional.

Además, esta situación plantea otros interrogantes. ¿Esa restricción del recurso de amparo ha permitido que el Tribunal Constitucional cumpla mejor sus otras funciones? El nuevo requisito de la especial trascendencia constitucional ¿impone una objetivación absoluta del recurso de amparo, o, por el contrario, admite mantener la dimensión subjetiva del mismo en ciertos casos? Ambos interrogantes son de calado y su respuesta fundada y reflexiva aconseja su atención en otro momento y lugar. Sin embargo, no se puede dejar de anticipar que, de modo semejante a lo que sucede en otros ordenamientos jurídicos avanzados, como en el de Estados Unidos de América o en el de Alemania, debiera mantenerse abierta también en la admisión a trámite la dimensión subjetiva del recurso de amparo como garantía de los derechos fundamentales y libertades públicas frente al ejercicio abusivo del poder público.

\section{Bibliografía}

ÁlVAREZ CONDE, Enrique y TUR AUSINA, Rosario, Derecho Constitucional, Tecnos, 2014, Madrid, España.

ARAGÓN REYES, Manuel, "La reforma de la Ley Orgánica del Tribunal Constitucional”, Revista Española de Derecho Constitucional, núm. 85 de 2009, Madrid, España, Centro de Estudios Políticos y Constitucionales.

BACHMAIER WINTER, Lorena, "La reforma del recurso de amparo en la Ley orgánica 6/2007, de 24 de mayo”, Diario La ley, núm. 6775, 10 septiembre 2007, Madrid, España, Wolters Kluwer. 
BORRAJO INIESTA, Ignacio, "Mitos y realidades de la jurisdicción constitucional de amparo: hechos, derecho, pronunciamientos, admisión, costes", Teoría E Derecho. Revista de Pensamiento Jurídico, núm. 3 de 2008, Valencia, España, Tirant lo Blanch.

BORRAJO INIESTA, Ignacio y ELÍAS MÉNDEZ, Cristina, "La puesta en marcha del nuevo recurso de amparo y otras facetas de la jurisprudencia constitucional", Revista General de Derecho Constitucional, núm. 8, 2009, Iustel, España.

CABAÑAS GARCÍA, Juan Carlos, "El recurso de amparo que queremos", Revista Española de Derecho Constitucional, núm. 88 de 2010, Madrid, España, Centro de Estudios Políticos y Constitucionales.

CARRERAS SERRA, Francesc de, "Una interpretación moderadamente optimista del nuevo recurso de amparo", Parlamento y Constitución. Anuario, núm. 11 de 2008, Cortes de Castilla-La Mancha, Toledo, España.

CARRILLO, Marc, "La objetivación del recurso de amparo: una necesidad ineludible”, Revista Vasca de Administración Pública, núm. 81 de 2008, Instituto Vasco de Administración Pública, Guipúzcoa, España.

DE LA OLIVA SANTOS, Andrés, "La perversión jurídica del amparo constitucional en España", Actualidad Jurídica Aranzadi, núm. 751 de 2008, Editorial Aranzadi, Navarra, España.

ESPAÑA, Tribunal Constitucional, http://www.tribunalconstitucional.es/ es/LeyTransparencia/informacionInstitucional/memorias/Paginas/default_05. aspx.

ESPAÑA, Tribunal Constitucional, Sentencia (Pleno) 12/1982 de 31 marzo, Ponente Luis Díez-Picazo.

ESPAÑA, Tribunal Constitucional, Sentencia (Pleno) 45/1986, de 17 de abril, Ponente Miguel Rodríguez-Piñero y Bravo-Ferrer.

ESPANA, Tribunal Constitucional, Sentencia (Pleno) 234/2000, de 3 de octubre, Ponente Pedro Cruz Villalón.

ESPANAA, Tribunal Constitucional, Sentencia (Pleno) 155/2009, de 25 de junio, Ponente Vicente Conde Martín de Hijas.

ESPANAA, Tribunal Constitucional, Sentencia (Sala Primera) 107/1988, de 8 de junio, Ponente Eugenio Díaz Eimil.

GARBERÍ LLOBREGAT, José, "Requiem por el recurso de amparo constitucional”, Diario La ley, núm. 6775, 10 septiembre 2007, Madrid, España, Wolters Kluwer. 
FERNÁNDEZ FARRERES, Germán, "La reforma de la Ley Orgánica del Tribunal Constitucional”, Revista Española de Derecho Constitucional, núm. 81 de 2007, Madrid, España, Centro de Estudios políticos y Constitucionales.

HERNÁNDEZ RAMOS, Mario, "Propuesta de desarrollo del nuevo trámite de admisión del recurso de amparo: aspectos materiales y procedimentales", Revista de Las Cortes Generales, núm. 73 de 2008, Madrid, España, Congreso de los Diputados.

LÓPEZ GUERRA, Luis, ESPÍN Eduardo, GARCÍA MORILLO, Joaquín, PÉREZ TREMPS, Pablo, SATRÚSTEGUI, Miguel, Derecho Constitucional, V. I y II, Valencia, España, Tirant lo Blanch, 2010.

MATIA PORTILLA, Francisco Javier, "La especial trascendencia constitucional y la inadmisión del recurso de amparo", Revista Española de Derecho Constitucional, núm. 86 de 2009, Madrid, España, Centro de Estudios Políticos y Constitucionales.

NOGUEIRA GUASTAVINO, Magdalena, "La reforma del recurso de amparo por la LO 6/2007 del Tribunal Constitucional y su proyección laboral”, Revista General de Derecho del Trabajo y de la Seguridad Social, núm. 17, 2008, Iustel, España.

TENORIO, Pedro, El recurso de amparo ante el Tribunal Constitucional. Perspectivas de reforma, 2014, Madrid, España, Wolters Kluwer. 